\title{
APLIKASI DETEKSI DINI PERKEMBANGAN ANAK USIA 1 SAMPAI 3 TAHUN BERBASIS ANDROID
}

\author{
Fajar Giri Gumilar ${ }^{1}$, Ade Mubarok ${ }^{2}$ \\ ${ }^{1}$ Universitas Adhirajasa Reswara Sanjaya \\ e-mail: fajargirigumilar@gmail.com \\ ${ }^{2}$ Universitas Adhirajasa Reswara Sanjaya \\ e-mail: adem@ars.ac.id
}

\begin{abstract}
Abstrak
Perkembangan anak usia dini memiliki peranan yang sangat penting dalam perkembangan seorang individu. Agar seorang anak memiliki perkembangan yang baik, maka perlu ada deteksi dini tumbuh kembang anak yang memiliki tujuan tercapainya optimalisasi perkembangan seorang anak. Sangat disayangkan masih sedikit orang tua yang memiliki kesadaran untuk melakukan deteksi dini tumbuh kembang anak ini. Metode deteksi dini perkembangan anak ini menggunakan media berbasis android. Tujuan penelitian ini adalah untuk membuat sebuah aplikasi deteksi dini perkembangan anak yang berusia 1 sampai 3 tahun berbasis android. Aplikasi ini ditujukan bagi orang tua serta tim medis kesehatan yang bertugas guna memberikan informasi mengenai perkembang anak, menemukali penyimpangan pertumbuhan dan dapat memberikan saran stimulasi dini apa yang harus di berikan kepada anak. Dari hasil pengujian yang dilakukan terhadap Aplikasi Deteksi Dini Perkembangan anak Usia 1 sampai 3 Tahun, maka dapat disimpulkan hasil Layout sudah sesuai dengan layout yang didesign dan Setiap tombol maupun form sudah berfungsi sesuai dengan kebutuhan aplikasi.
\end{abstract}

Kata Kunci : Perkembangan Anak, Stimulasi Anak, Teknologi Informasi dan Komunikasi, Android

\begin{abstract}
Early childhood development plays a very important role in the development of an individual. In order for a child to have good development, it is necessary to detect early child development and development which has the goal of optimizing the development of a child. It is very unfortunate that there are still few parents who have the awareness to do early detection of this child's development and development. This method of early detection of child development uses android-based media. The purpose of this study is to create an Android-based early detection application for the development of children aged 1 to 3 years. This application is intended for parents and the health medical team whose task is to provide information about child development, identify growth deviations and can provide advice on what early stimulation should be given to children. From the results of tests carried out on the Early Detection Application for the development of children aged 1 to 3 years, it can be concluded The layout results are in accordance with the designed layout and Each button or form is functioning according to application needs.
\end{abstract}

Keywords: Child Development, Child Stimulation, Information and Communication Technology, Android 


\section{Pendahuluan}

Perkembangan anak dan pertumbuhan anak mempunyai dua fase yaitu pertumbuhan merupakan suatu proses perubahan fisik. Kondisi ini seperti berkembangnya ukuran organ tubuh seperti tinggi maupun berat badan dan perkembangan merupakan suatu proses bertambahnya kemampuan dan struktur dan fungsi tubuh yang lebih kompleks seperti kaki utntuk berjalan. Beberapa kasus pada balita Indonesia mengalami gangguan perkembangan seperti perkembangan motoric halus dan motoric kasar, gangguan pada pendengaran, gangguan kecerdasan dan gangguan keterlambatan bicara. Berdasarkan hal tersebut puskesmas diciptakan untuk melayani kesehatan masyarakat. Tetapi keaktifan orang tua dalam melakukan pengawasan tumbuh kembang anaknya mengalami penurunan, hal tersebut bias disebabkan oleh beberapa faktor seperti kesibukan ataupun faktor lainnya (Saurina, 2016).

Perkembangan pada anak usia dini memegang peranan yang sangat penting dalam proses perkembangan seorang individu. Untuk mendapatkan anak yang memiliki perkembangan baik, maka diperlukan proses deteksi dini tumbuh kembang anak yang memiliki tujuan utama tercapainya perkembangan seorang anak secara optimal. Sangat disayangkan masih sedikit orang tua yang memiliki kesadaran untuk melakukan deteksi dini tumbuh kembang anak ini (Fazrin et al., 2018).

Orang tua merupakan pihak yang sangat berpengaruh dalam pemantauan maupun untuk pemenuhan kebutuhan perkembangan anak terutama pada lima tahun kehidupan yang merupakan masa keemasan bagi perkembangan anak. Data menunjukkan peningkatan prevalensi orangtua yang tidak melakukan pemantauan perkembangan anak berkala, padahal pemantauan perkembangan anak selaras dengan deteksi dini gangguan perkembangan anaksehingga intervensi dan simulasi dapat memberikan hasil yang optimal (Simanjuntak et al., 2017).

Balita merupakan masa periode emas (golden age) sebagai masa yang sangat penting untuk memperhatikan tumbuh kembang anak secara cermat, agar sedini mungkin ibu dapat mengetahui apabila terjadi kelainan pada anaknya. Kelainan yang tidak terdeteksi pada masa ini akan berdampak negatif terhadap tahapan pencapaian pertumbuhan dan perkembangan balita selanjutnya. Ibu sebagai edukator yang paling dekat terhadap balita masih belum mengetahui lebih banyak proses tumbuh kembang balitanya,biasanya ibu baru menyadari adanya kelainan setelah segalanya sudah terlambat (Sudirman, Hartati \& Wulansari, 2017).

Pada masa perkembangan balita, masalah stunting dapat menjadi sebuah masalah yang berbahaya apabila tidak diatasi dengan baik. Dampak yang dapat ditimbulkan masalah stunting seperti gangguan pada metabolisme, menurunnya sistem kekebalan tubuh, kemampuan kognitif, gangguan pada pertumbuhan fisik, dan kualitas kerja yang tidak kompetitif. ASI eksklusif menjadi salah satu faktor yang dapat mempengaruhi prevalensi stunting karena nutrisi yang terkandung dalam ASI merupakan salah satu faktor penting yang menentukan masa perkembangan anak (Handayani, Kapota \& Oktavianto, 2019).

Anak-anak umumnya akan tumbuh dan juga berkembang dengan baik apabila segala kebutuhannya dapat dipenuhi secara optimal. Apabila salah satu kebutuhan asuh, asih, ataupun asah tidak terpenuhi dengan baik maka akan terjadi kekurangan dalam tumbuh kembangnya. Dampak tersebut dapat terjadi secara langsung atau tidak langsung. Begitupun untuk dampak jangka pendek dan jangka panjang. Pertumbuhan dan perkembangan anak yang mengalami pelecehan anak (child abuse), padaumumnya lebih lambat dari pada anak yang normal (Widiastuti \& Sekartini, 2016).

Deteksi dini pada masalah perkembangan anak sangat berpengaruh dalam menentukan keberhasilan yang dapat berdampak pada plastisitas otak maksimal di dalam melakukan kompensasi penyimpangan perkembangan. Deteksi dini terhadap gangguan pada perkembangan anak sangat menentukan nilai dari intervensi yang akan diberikan sehingga akan mempengaruhi perkembangan kognitif secara menyeluruh (Hartanto et al., 2016). Penelitian lainnya tentang deteksi dini pertumbuhan dan perkembangan anak sudah pernah dilakukan juga oleh (Wulandari \& Pangastuti, 2020)

Aplikasi diagnosis berbasis android juga pernah dilakukan pada penelitian (Paramitha et al., 2019) karena simple dalam dan memudahkan proses aksesnya. 


\section{Metode Penelitian}

Metode penelitian ini dilakukan dengan beberapa tahapan sebagai berikut:

1. Pengumpulan data

Penelitian ini memerlukan data yang diambil oleh penulis merupakan data deteksi dini perkembangan anak usia 1 sampai 3 tahun untuk mendeteksi dini adanya penyimpangan pertumbuhan anak dengan menggunakan usia anak, berat badan dan tinggi badan anak. Data tersebut didapatkan dari jurnal dan buku terkait deteksi dini perkembangan anak.

2. Desain Aplikasi

Desain aplikasi yang dibangung oleh penulis menggunakan android studio dan menggunakan bahasa pemrograman java. Kebutuhan yang sudah dianalisa dalam bentuk desain interface dan desain struktur data menggunakan UML.

3. Testing

Dalam tahap ini penulis melakukan pengujian aplikasi sistem menggunakan black box testing untuk menguji apakah aplikasi berjalan dengan benar dan sesuai.

\section{Metode Pengembangan Aplikasi}

Metode pengembangan aplikasi yang digunakan dalam pembuatan aplikasi deteksi dini perkembangan anak usia 1 sampai 3 tahun dengan model pendapatan SDLC (System Development Life Cycle) dalam bentuk waterfall (air terjun). Terdapat beberapa tahapan diantaranya adalah requirement definition, softweare design, implementation and unit testing, verification and system testing dan operation and maintenance.

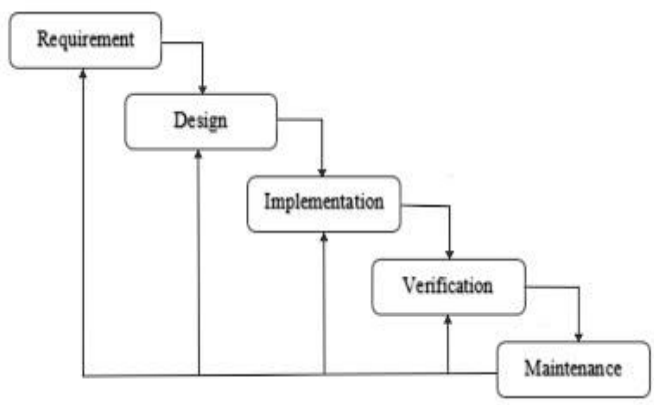

Gambar 1. Metode Pengembangan SDLC
1. Requirement Definition

Dalam tahapan ini penulis melihat dari penelitian sebelumnya untuk mendapatkan data-data mengenai deteksi perkembangan anak usia 1 sampai 3 tahun untuk melengkapi data aplikasi ini.

\section{Software Design}

Dalam tahap ini penulis membagi kebutuhan hardware dan software yang akan digunakan dalam pembuatan aplikasi deteksi dini perkembangan anak usia 1 sampai 3 tahun. Penulis membuat perancangan dengan UML, use case diagram, activity diagramdan sequence diagram.

3. Implementation and Unit Testing

Dalam tahap ini penulis melakukan testing menggunakan blackbox yang menguji terhadap detail perancangan aplikasi deteksi dini perkembangan anak usia 1 sampai 3 tahun.

4. Verification

Dalam tahap ini penulis akan mengintegrasikan sistem ke bentuk print out berupa laporan untuk di verifikasi.

\section{Operation and Maintenance}

Penulis akan melakukan pemeliharaan perangkat komputer yang digunakan agar tetap berjalan dengan baik.

\section{Hasil dan Pembahasan}

Pada tahap ini difokuskan pada desain software architecture dan user interface dalam pembuatan aplikasi deteksi dini perkembangan anak usia 1 sampai 3 tahun berbasis android.

\subsection{Analisis Sistem dan Perancangan} Diagram

Dalam tahap ini penulis menggunakan model UML dalam perancangan diagram. Berikut UML aplikasi deteksi dini perkembangan anak usia 1 sampai 3 tahun. 
A. Use Case Diagram

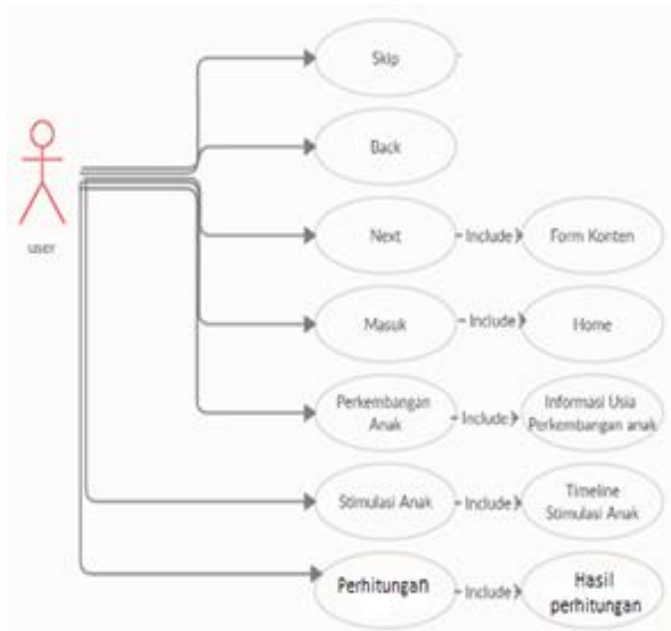

Gambar 2. Use Case Diagram Aplikasi

B. Activity Diagram

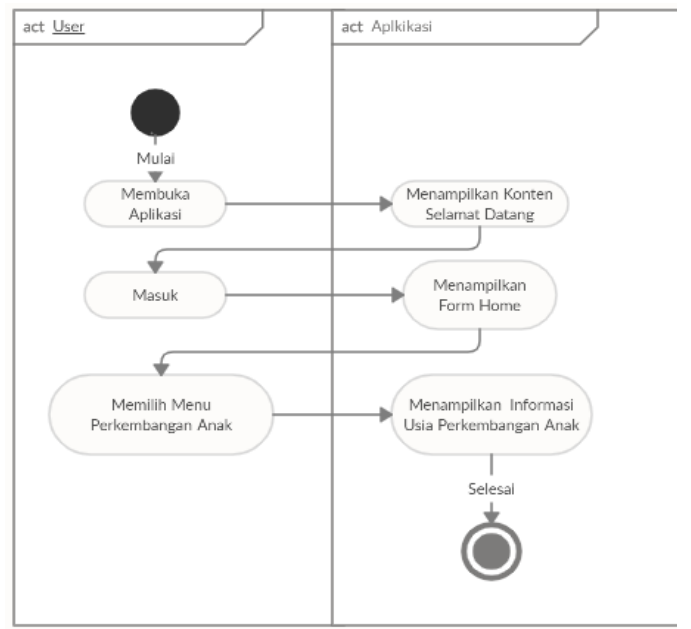

Gambar 3. Activity Diagram Menu

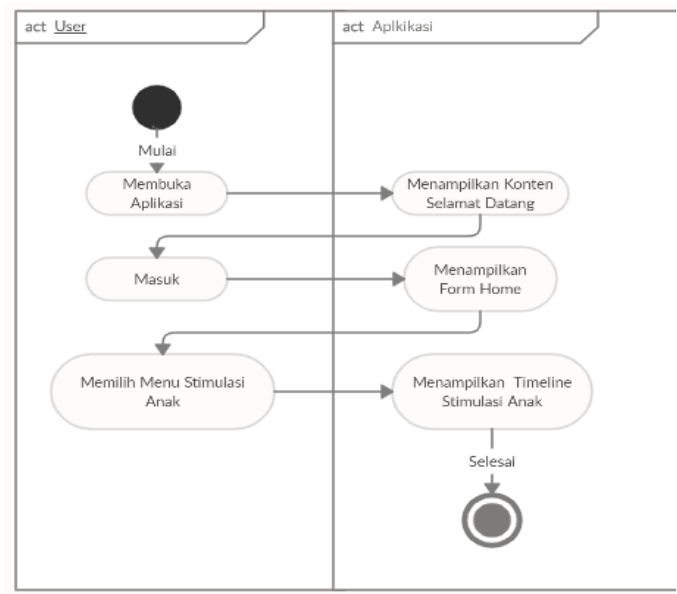

Gambar 4. Activity Diagram Menu

Stimulasi

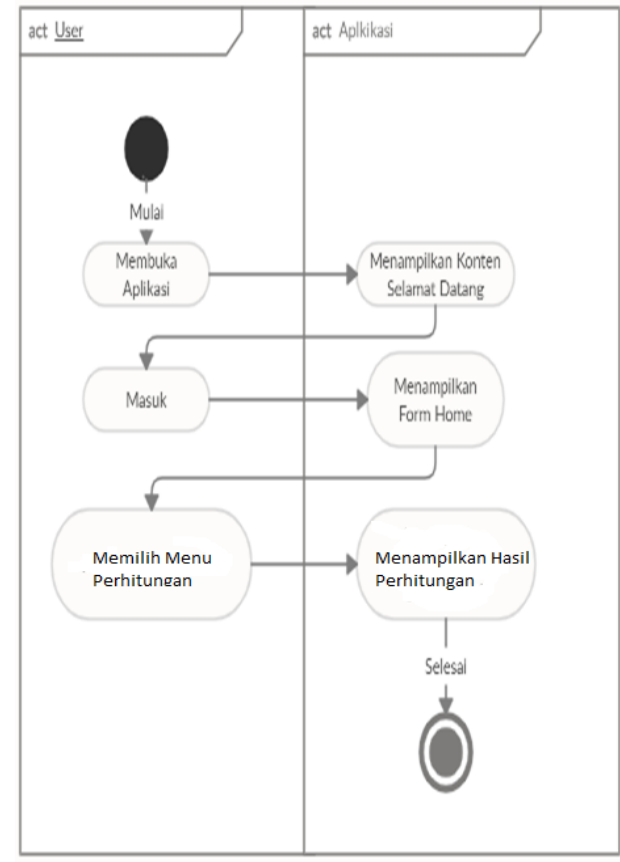

Gambar 5. Activity Diagram Menu Perhitungan

C. Sequence Diagram

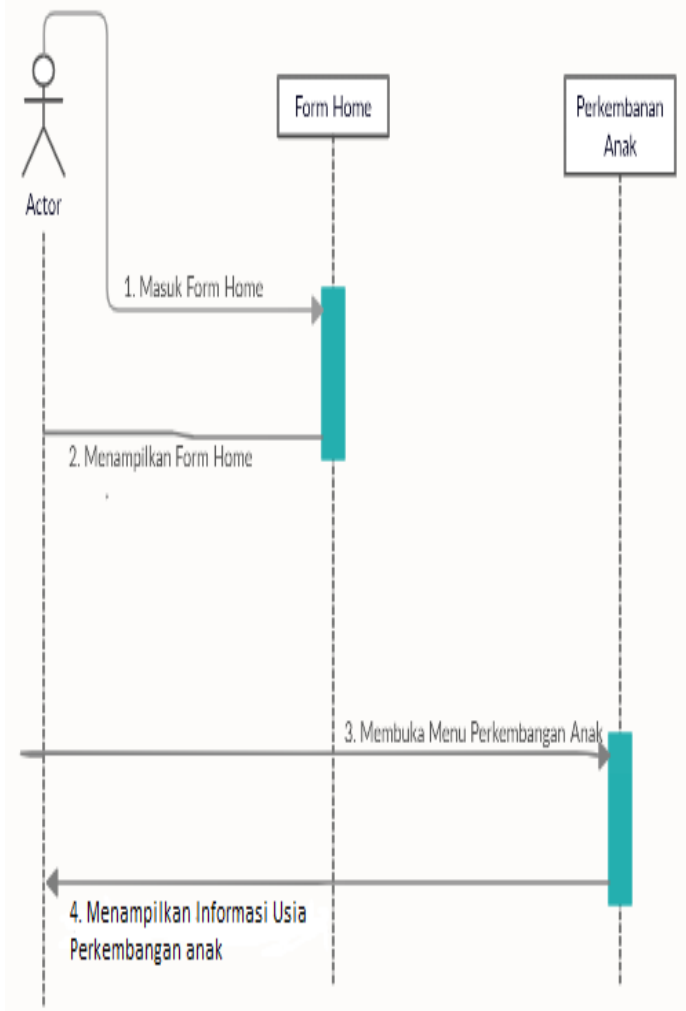

Gambar 6. Sequence Diagram Menu 


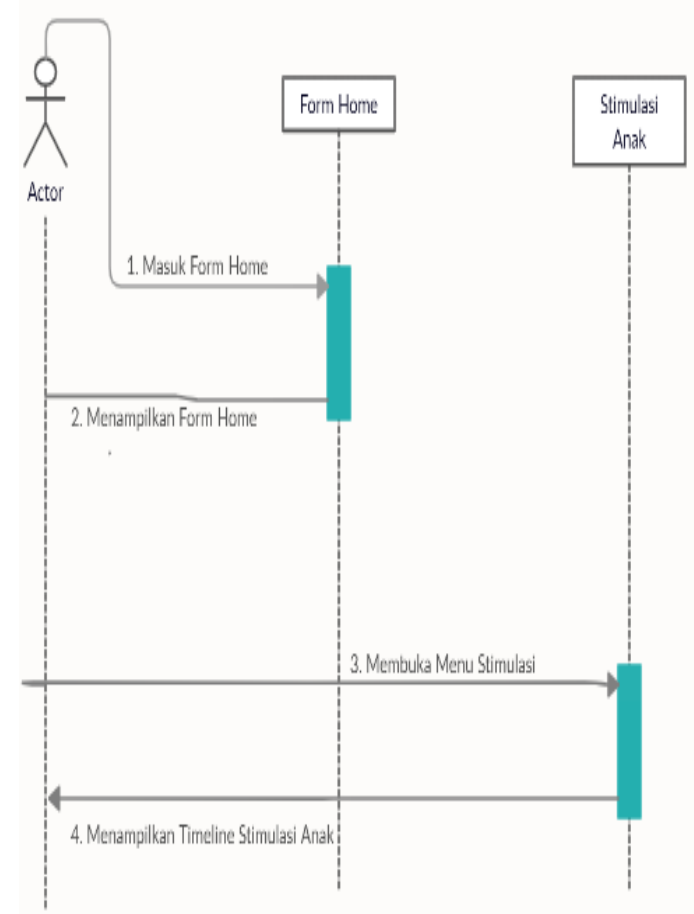

Gambar 7. Sequence Diagram Menu Stimulasi

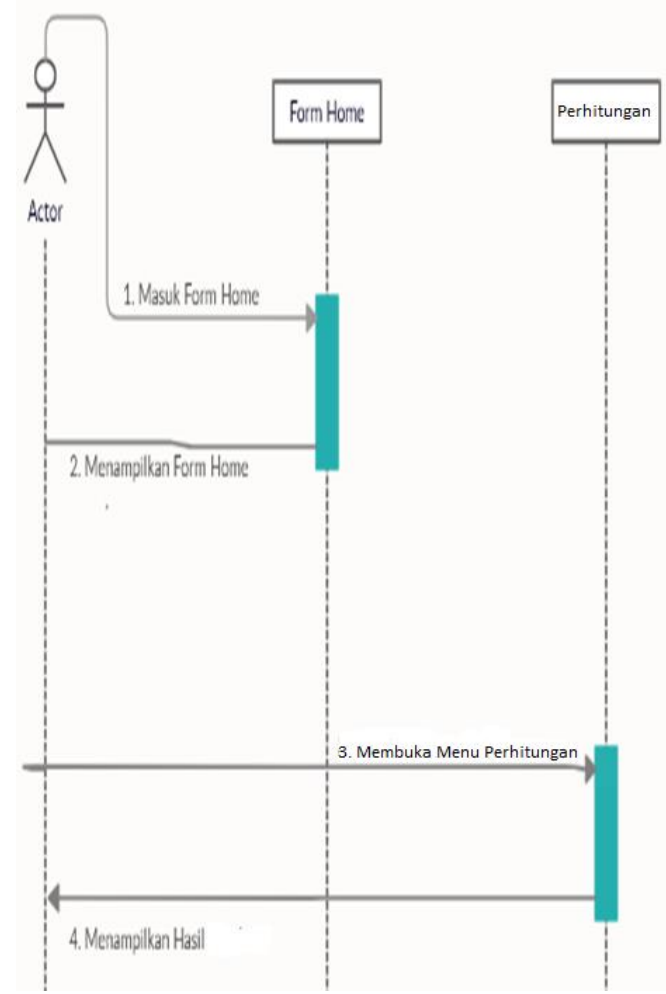

Gambar 8. Sequence Diagram Menu Perhitungan

\subsection{Tampilan Aplikasi}

A. Tampilan Konten Awal

Tampilan ini berupa konten selamat datang.

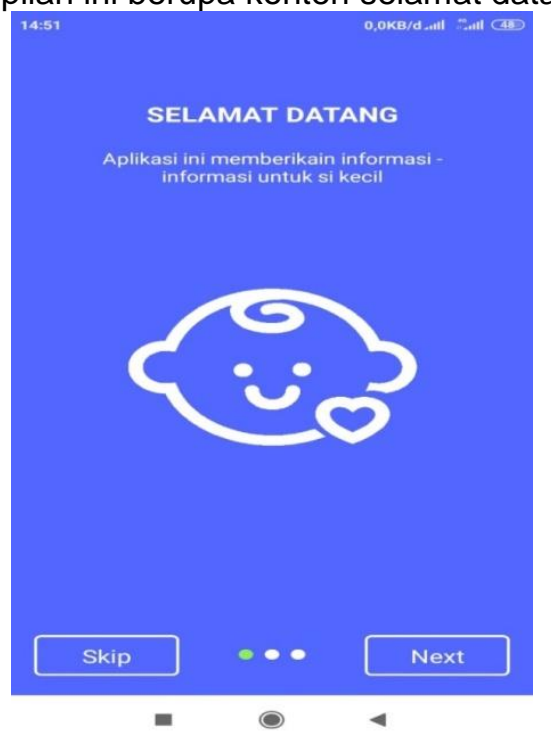

Gambar 9. Tampilan Awal

\section{B. Halaman Login}

Tampilan ini berupa halaman masuk yang harus di isi dengan nama untuk menuju ke halaman utama atau beranda.

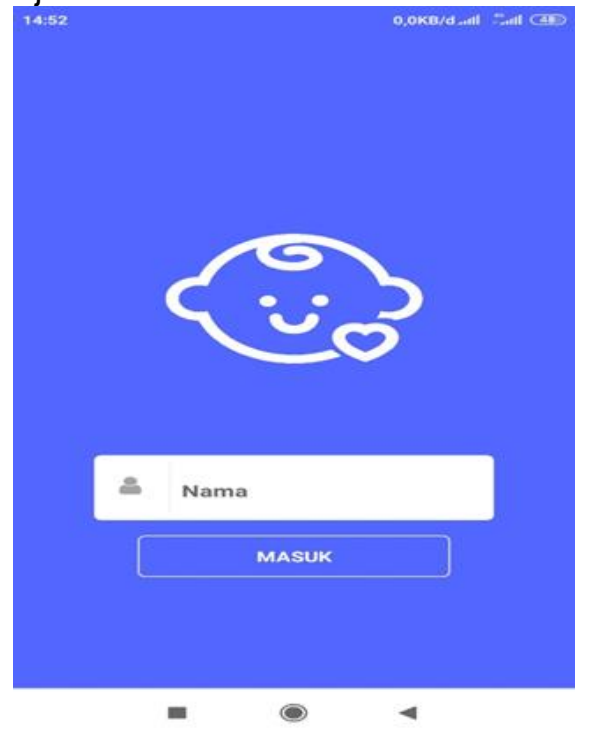

Gambar 10. Halaman Login

\section{Halaman Beranda}

Halaman beranda dapat dilihat setelah melakukan pengisian nama di tampilan masuk. Terdapat beberapa menu di dalam halaman beranda 

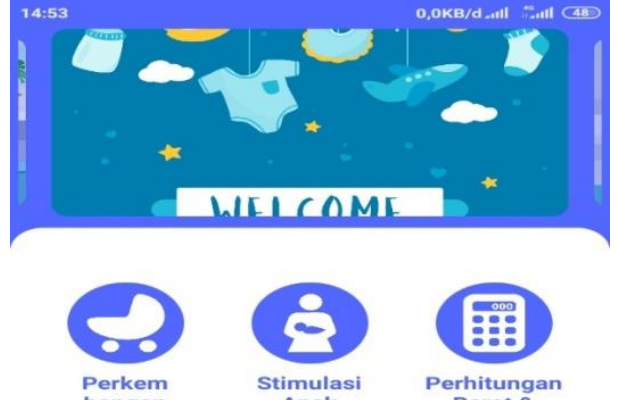

Anak

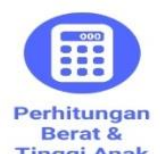

Berat \&

Pangan

Baca Artikel

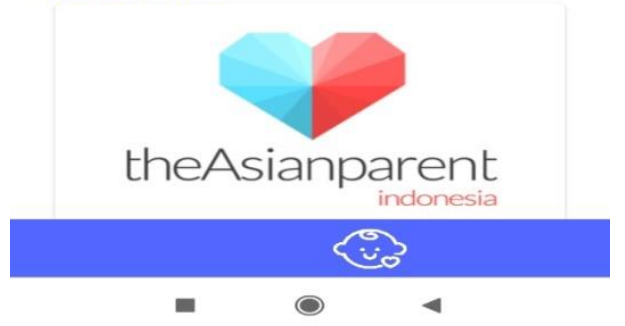

Gambar 11. Halaman Beranda

\section{Tampilan Menu Perkambangan Anak} Tampilan ini berupa informasi tentang perkembangan anak sesuai usia.

\begin{tabular}{l} 
Pilih Umur \\
\hline $0-1$ Tahun \\
25:19 Tahun
\end{tabular}

Gambar 12. Tampilan Menu Perkembangan Anak

\section{E. Tampilan Menu Stimulasi Anak}

Tampilan ini berupa informasi tentang stimulasi anak sesuai usia.

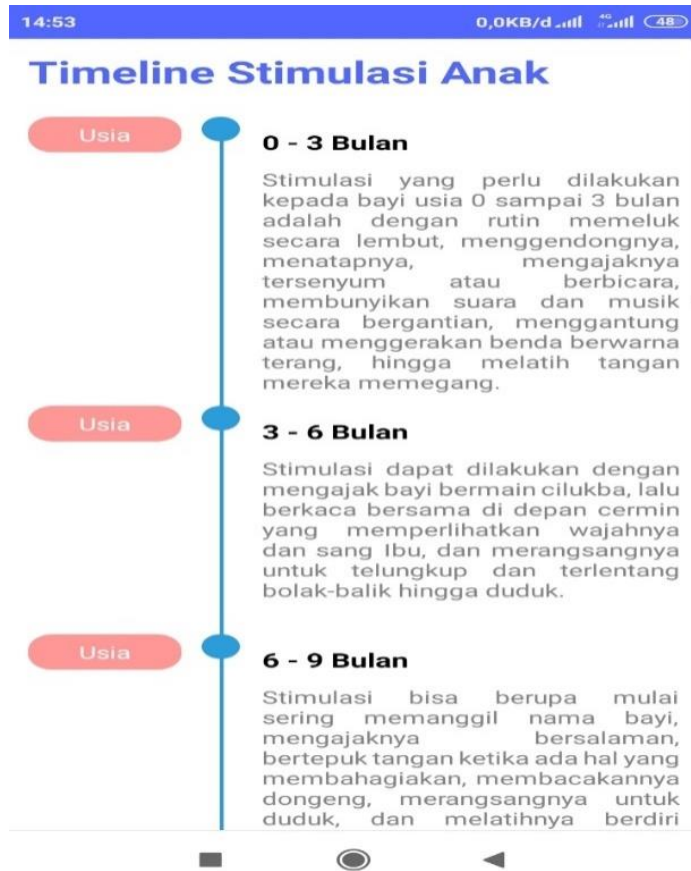

Gambar 13. Tampilan Menu Stimulasi Anak

\section{F. Tampilan Menu Perhitungan}

Tampilan ini berupa perhitungan berat badan dan tinggi badan anak sesuai usia dan akan menampilkan hasilnya.

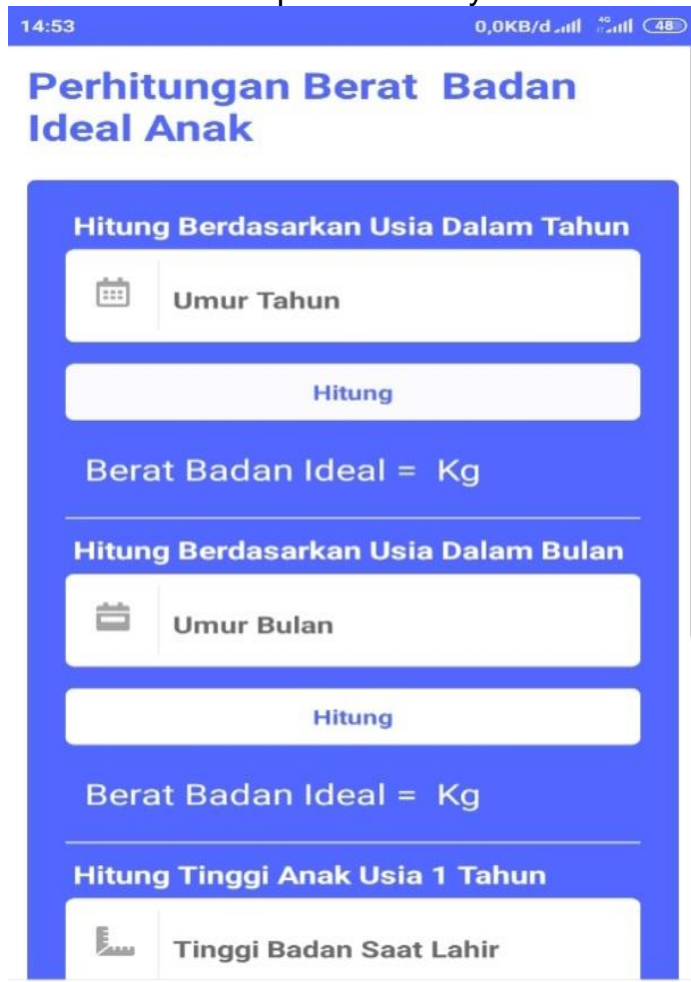

\section{Perhitungan Berat Badan Ideal Anak}

ung Berdasarkan Usia Dalam Tahun

Hitung

\section{Berat Badan Ideal $=\mathrm{Kg}$ \\ Hitung Berdasarkan Usia Dalam Bulan}

Gambar 14

Tampilan Menu Perhitungan 


\section{Kesimpulan}

Setelah melakukan pembuatan aplikasi deteksi dini perkembangan anak usia 1 sampai 3 tahun berbasis android. Maka dari itu dapat diambil kesimpulan sebagai berikut:

1. Aplikasi android ini agar lebih mempermudah orang tua dalam mengecek ukuran tinggi dan berat badan anak.

2. Aplikasi ini memudahkan orang tua jika ingin mengetahui ukuran berat dan tinggi badan yang ideal.

\section{Saran}

Setelah melakukan pembuatan aplikasi deteksi dini perkembangan anak usia 1-3 tahun berbasis android, Maka penulis akan memberikan saran agar aplikasi deteksi dini perkembangan anak ini bisa lebih baik dan tampilan yang lebih bagus dan menarik. Saran tersebut seperti penambahan jenis perhitungan data agar lebih banyak dan bervariasi dan penambahan tamplian proses perhitungan agar bisa lebih di kembangkan.

\section{Referensi}

Fazrin, I., Widiana, D., Trianti, I. R., Baba, K. J., Amalia, M. N., \& Smaut, M. Y. (2018). Pendidikan Kesehatan Deteksi Dini Tumbuh Kembang pada Anak di Paud Lab School UNPGRI Kediri. Journal of Community Engagement in Health, 1(2), 6-14.

Handayani, S., Kapota, W. N., \& Oktavianto, E. (2019). Hubungan status asi eksklusif dengan kejadian stunting pada batita usia 24-36 bulan di Desa Watugajah Kabupaten Gunungkidul. Medika Respati: Jurnal Ilmiah Kesehatan, 14(4), 287-300.

Hartanto, F., Selina, H., Zuhriah, H., \& Fitra, S. (2016). Pengaruh perkembangan bahasa terhadap perkembangan kognitif anak usia 1-3 tahun. Sari Pediatri, 12(6), 386-90.

Paramitha, N., Junianto, E., \& Susanti, S. (2019). Penerapan Teorema Bayes Untuk Diagnosis Penyakit Pada Ibu Hamil Berbasis Android. Jurnal Informatika, 6(1), 53-61.
Saurina, N. (2016). Aplikasi Deteksi Dini Tumbuh Kembang Anak Usia Nol Hingga Enam Tahun Berbasis Android. Jurnal Buana Informatika, $7(1)$, pp. 65-74. doi: 10.24002/jbi.v7i1.485.

Simanjuntak, C. A., Fitri, A. D., \& Puspasari, A. (2017). Deteksi Dini Dan Edukasi Orang Tua Tentang Gangguan Tumbuh Kembang Balita. Jurnal Karya Abdi Masyarakat, 1(1), 14-17.

Sudirman, S., Hartati, H., \& Wulansari, A. (2017). Hubungan pengetahuan ibu dengan tahap pencapaian tumbuh kembang balita usia 4-5 tahun di kelurahan medono Kota pekalongan. Jurnal Pemerintah Kota Pekalongan, 12.

Widiastuti, D., \& Sekartini, R. (2016). Deteksi dini, faktor risiko, dan dampak perlakuan salah pada anak. Sari Pediatri, 7(2), 105-12.

Wulandari, H., \& Pangastuti, R. (2020). Pengembangan Aplikasi Kesehatan Berbasis Mobile Untuk Pemantauan Deteksi Dini Tumbuh Kembang (DDTK) Anak Usia 4-6 Tahun. AlAthfaal: Jurnal IImiah Pendidikan Anak Usia Dini, 3(1), 98-111. 